\title{
Refractory Transformed Non-Hodgkin Lymphoma
}

National Cancer Institute

\section{Source}

National Cancer Institute. Refractory Transformed Non-Hodgkin Lymphoma. NCI

Thesaurus. Code C140091.

An indolent non-Hodgkin lymphoma which has undergone histologic transformation to an aggressive non-Hodgkin lymphoma and has become resistant to treatment. 